\title{
Determining the Position of Tip of Maxillary Canines in Relation to Commissure of Mouth and Midpupillary Line and its Correlation with Square, Ovoid and Tapering Arch Form
}

\author{
Mishra $\mathrm{S}^{1}$, Mathema SRB ${ }^{2}$ \\ ${ }^{1}$ Assistant Professor, Department of Prosthodontics and Maxillofacial Prosthetics, Chitwan Medical College and \\ Hospital, Bharatpur, Nepal \\ ${ }^{2}$ Professor, Department of Prosthodontics and Maxillofacial Prosthetics, People's Dental College and Hospital, \\ Kathmandu, Nepal
}

\begin{abstract}
Introduction: Selection of appropriately sized maxillary denture teeth in various types of arch form is often a challenging aspect during complete denture rehabilitation. The correlation of facial anatomical landmarks may serve as a reliable predictor for the selection of teeth.

Materials and methods: The maxillary arch impression of 113 dentate subjects were made, casts poured and divided into square, ovoid and tapering arch form. The position of tip of maxillary canines in relation to commissure of mouth and midpupillary line were determined by using vacuum formed template and pupillometer respectively.

Results: The result showed the significant difference in mean distance from commissure to canine tip $(\mathrm{p}<0.001)$ and IPD $(\mathrm{p}<0.017)$ among square, ovoid and tapering arch form.

Conclusion: The commissure of lip may serve as a reliable guideline for selection of anterior teeth according to arch form and IPD/ICW can similarly be used to determine anterior teeth width.
\end{abstract}

Key words: Tip of maxillary canine, commissure of lip, interpupillary distance, arch form

\section{Introduction}

$\mathrm{E}$ sthetics is one of the prime concerns for patients seeking prosthodontic rehabilitation. In order to satisfy the esthetic requirement, prosthetic rehabilitation should aim to restore optimal dentolabial relations in harmony with the overall facial appearance, thereby reflecting the naturalness and individuality of the patient. Selection of appropriately sized anterior teeth during

\section{Conflict of Interest: No}

*Corresponding Author
Dr. Srijana Mishra
Assistant Professor
Department of Prosthodontics and Maxillofacial
Prosthetics
Chitwan Medical College and Hospital, Bharatpur,
Nepal
E-mail: srij_mishra@yahoo.com

prosthodontic rehabilitation is a complex process particularly when there are no preextraction records. ${ }^{1,2}$

Numerous facial and intraoral measurements have also been proposed as a guideline to assist clinician for selection of artificial teeth. Some of routinely used anatomical landmarks include width of the mouth, interalar width, bizygomatic width, interpupillary distance and intercanthal distance. ${ }^{2,}{ }^{3}$ Moreover, the issues regarding the reliability of selection of teeth based on these guidelines arises due to individual anatomical variations such as arch form. ${ }^{3}$

Knowledge of an arch form as an anatomical parameter is of considerable reliance, especially regarding the positioning and selection of anterior teeth for artificial prosthesis. ${ }^{4}$ Among the maxillary anterior teeth, the position of maxillary canine appears to be more predictable 
determinant for selection of width of anterior teeth relative to others. ${ }^{5}$

\section{Materials and Methods}

This clinical study was carried out on 113 dentate subjects meeting the inclusion criteria. Impression of maxillary arch were made using irreversible hydrocolloid impression material and casts were poured using Type III dental stone. All casts were divided into square, ovoid and tapering arch form. Transparent template were fabricated on each cast. The position of the tip of maxillary canines in relation to commissure of mouth for each subject were marked on buccal surface of template and transferred to corresponding cast. The distance between the marks corresponding to commissure and tip of the canine on both sides were measured using digital vernier caliper. The measurement done for each subject were recorded and then subdivided according to relation to commissure of mouth into at commissure, medial to commissure or distal to commissure. The measurement of interpupillary distance was obtained directly from the subject by using calibrated caliper like device as manual pupillometer. The measurement of intercanine width was done directly from maxillary cast. Then the calculation of distance of tip of canine from midpupillary line for each side was done by deducting the ICW from IPD and then dividing by two. All the data were recorded and statistically analyzed.

\section{Results}

The mean position of tip of maxillary canine is mesial to commissure of mouth by $2.87 \pm$ $1.01 \mathrm{~mm}$ in square, $1.97 \pm 0.97 \mathrm{~mm}$ in ovoid and $0.72 \pm 0.92 \mathrm{~mm}$ in tapering arch form. Comparison of means showed that there is statistically significant difference in mean distance from commissure to canine tip $(p<0.001)$ among the three arch forms signifying a positive association between mean distance from commissure to canine tip $(\mathrm{p}<0.001)$ with ovoid, square and tapering arch forms. The mean position of tip of maxillary canine is mesial to midpupillary line by $11.87 \pm 2.32 \mathrm{~mm}$ in square, $11.54 \pm 1.42 \mathrm{~mm}$ in ovoid and $11.05 \pm 1.73 \mathrm{~mm}$ in tapering arch form. Comparison of mean among square, ovoid and tapering arch form showed that there was no significant difference in mean distance from midpupillary line to canine tip among three arch form indicating a weak positive correlation. The mean IPD in square arch form was $60.38 \pm 2.23 \mathrm{~mm}$, in ovoid arch form was $59.44 \pm 2.24 \mathrm{~mm}$ and in tapering arch form was $58.69 \pm 3.06 \mathrm{~mm}$. Comparison of means showed that there was significant difference in mean distance of IPD $(p<0.017)$ among the three arch forms. The mean value of ratio between interpupillary distance/intercanine width was $1.61 \pm 0.10$ with a narrow range of $1.34-1.96 \mathrm{~mm}$. Intercanine width has a positive correlation with interpupillary distance.

Table 1: Descriptive statistics for the continuous study variables. $(n=113)$

\begin{tabular}{|c|c|c|c|c|}
\hline \multirow[b]{2}{*}{ Study Variables } & \multicolumn{2}{|c|}{ Mean } & \multirow{2}{*}{$\begin{array}{c}\text { Std. } \\
\text { Deviation }\end{array}$} & \multirow{2}{*}{$\begin{array}{c}\text { Range } \\
\text { (lower-Upper) }\end{array}$} \\
\hline & Value & Std. Error & & \\
\hline Age of the study participants & 24.01 & 0.40 & 4.28 & $18-38$ \\
\hline Distance from commissure to tip of canine & 1.90 & 0.12 & 1.30 & $0.0-4.92$ \\
\hline Distance between canine tip to midpupillary line & 11.5 & 0.17 & 1.88 & $6.88-22.86$ \\
\hline Inter pupillary distance (IPD) & 59.5 & 0.24 & 2.59 & $54.0-65.0$ \\
\hline Intercanine width(ICW) & 36.7 & 0.21 & 2.33 & $31.30-42.29$ \\
\hline Ratio between IPD/ICW & 1.61 & 0.01 & 0.10 & $1.34-1.96$ \\
\hline
\end{tabular}


Table 2: Location of tip of canine with respect to commissure of lip. $(n=113)$

\begin{tabular}{|l|c|c|}
\hline Location of the canine tip & Frequency (n) & Percent (\%) \\
\hline At the commissure & 15 & $13.3 \%$ \\
\hline Medial to the commissure & 98 & $86.7 \%$ \\
\hline Distal to the commissure & 0 & 0 \\
\hline
\end{tabular}

*statistically significant.

Table 3: Pearson's correlation of distance between IPD and ICW.

\begin{tabular}{|c|c|c|c|c|c|}
\hline \multicolumn{2}{|l|}{ Correlation } & $\begin{array}{c}\text { Correlation } \\
\text { Coefficient (r) }\end{array}$ & \multicolumn{2}{|c|}{$\begin{array}{c}\text { Coefficient of } \\
\text { Determination }\left(\mathbf{R}^{2)}\right.\end{array}$} & $P$ value \\
\hline Between IPD and ICW & & +0.214 & \multicolumn{2}{|c|}{0.046} & $0.023^{*}$ \\
\hline \multicolumn{6}{|l|}{ *statistically significant. } \\
\hline \multirow{2}{*}{ Arch Forms } & \multicolumn{3}{|c|}{ Sex } & \multirow{2}{*}{$\begin{array}{l}\text { Chi square } \\
\text { value }\end{array}$} & \multirow{2}{*}{$P$ value } \\
\hline & Male (n, \%) & \multicolumn{2}{|c|}{ Female (n, \%) } & & \\
\hline Ovoid & $7(18.9 \%)$ & \multicolumn{2}{|c|}{$32(42.1 \%)$} & \multirow{3}{*}{6.267} & \multirow{3}{*}{$0.04 *$} \\
\hline Square & $17(45.9 \%)$ & \multicolumn{2}{|c|}{$22(28.9 \%)$} & & \\
\hline Tapering & $13(35.1 \%)$ & \multicolumn{2}{|c|}{$22(28.9 \%)$} & & \\
\hline
\end{tabular}

* statistically significant.

Table 5: Association of continuous parameters with various arch forms.

Results from Analysis of Variance (ANOVA).

\begin{tabular}{|l|c|c|c|c|c|}
\hline Parameters & $\begin{array}{c}\text { Ovoid } \\
(\mathbf{m e a n} \pm \mathbf{s d} \text { ) }\end{array}$ & $\begin{array}{c}\text { Square } \\
(\mathbf{m e a n} \pm \mathbf{s d} \text { ) }\end{array}$ & $\begin{array}{c}\text { Tapering } \\
(\mathbf{m e a n} \pm \mathbf{s d} \text { ) }\end{array}$ & F statistic & P value \\
\hline Age & $23.15 \pm 4.17$ & $25.15 \pm 4.66$ & $23.69 \pm 3.78$ & 02.31 & 0.103 \\
\hline Distance from commissure to canine tip & $01.97 \pm 0.97$ & $02.87 \pm 1.01$ & $0.72 \pm 0.92$ & 44.73 & $<0.01^{*}$ \\
\hline Distance from canine tip to MPL & $11.54 \pm 1.42$ & $11.87 \pm 2.32$ & $11.05 \pm 1.73$ & 01.80 & 0.169 \\
\hline Inter-pupillary distance (IPD) & $59.44 \pm 2.24$ & $60.38 \pm 2.23$ & $58.69 \pm 3.06$ & 04.22 & $0.017^{*}$ \\
\hline Inter-commissural width (ICW) & $36.32 \pm 2.23$ & $37.18 \pm 2.46$ & $36.66 \pm 2.28$ & 01.34 & 0.264 \\
\hline Ratio : IPD/ICW & $01.63 \pm 0.10$ & $01.62 \pm 0.10$ & $01.60 \pm 0.11$ & 0.83 & 0.437 \\
\hline
\end{tabular}

*statistically significant

Table 6: Post hoc comparisons of distance from commissure to canine tip among various arch forms.

\begin{tabular}{|c|c|c|c|c|c|c|}
\hline \multicolumn{2}{|c|}{ Dependent Variable } & \multirow{2}{*}{ Mean Diff. } & \multirow{2}{*}{ Std. Error } & \multicolumn{2}{c|}{$\mathbf{9 5 \%}$ Confidence Interval } & \multirow{2}{*}{ P value } \\
\cline { 3 - 6 } & Square & -0.896 & 0.221 & -1.421 & -0.371 & $<0.001^{*}$ \\
\hline \multirow{2}{*}{ Ovoid } & Tapering & 2.148 & 0.227 & 0.708 & 1.788 & $<0.001^{*}$ \\
\cline { 2 - 6 } & Ovoid & 0.896 & 0.221 & 0.371 & 1.421 & $<0.001^{*}$ \\
\hline \multirow{2}{*}{ Square } & Tapering & 2.145 & 0.227 & 1.605 & 2.684 & $<0.001^{*}$ \\
\hline \multirow{2}{*}{ Tapering } & Ovoid & -1.248 & 0.227 & -1.788 & -0.708 & $<0.001^{*}$ \\
\cline { 2 - 6 } & Square & -2.145 & 0.227 & -2.684 & -1.605 & $<0.001^{*}$ \\
\hline
\end{tabular}

*statistically significant. 
Mishra S et al.

Table 7: Post hoc comparisons of inter-pupillary distance among various arch forms.

\begin{tabular}{|c|c|c|c|c|c|c|}
\hline \multirow{2}{*}{ Dependent Variable } & \multirow{2}{*}{ Mean Diff. } & \multirow{2}{*}{ Std. Error } & \multicolumn{2}{c}{$\mathbf{9 5 \%}$ Confidence Interval } & \multirow{2}{*}{ P value } \\
\cline { 3 - 6 } Ovoid & Square & -0.949 & 0.571 & -2.31 & 0.41 & 0.225 \\
\cline { 2 - 6 } & Tapering & 0.750 & 0.588 & -0.65 & 2.15 & 0.411 \\
\hline \multirow{2}{*}{ Square } & Ovoid & 0.949 & 0.571 & -0.41 & 2.31 & 0.225 \\
\cline { 2 - 6 } & Tapering & 1.699 & 0.588 & 0.30 & 3.09 & $0.013^{*}$ \\
\hline \multirow{2}{*}{ Tapering } & Ovoid & -0.750 & 0.588 & -2.15 & 0.65 & 0.411 \\
\cline { 2 - 6 } & Square & -1.699 & 0.588 & -3.09 & -0.30 & $0.013^{*}$ \\
\hline
\end{tabular}

*statistically significant.

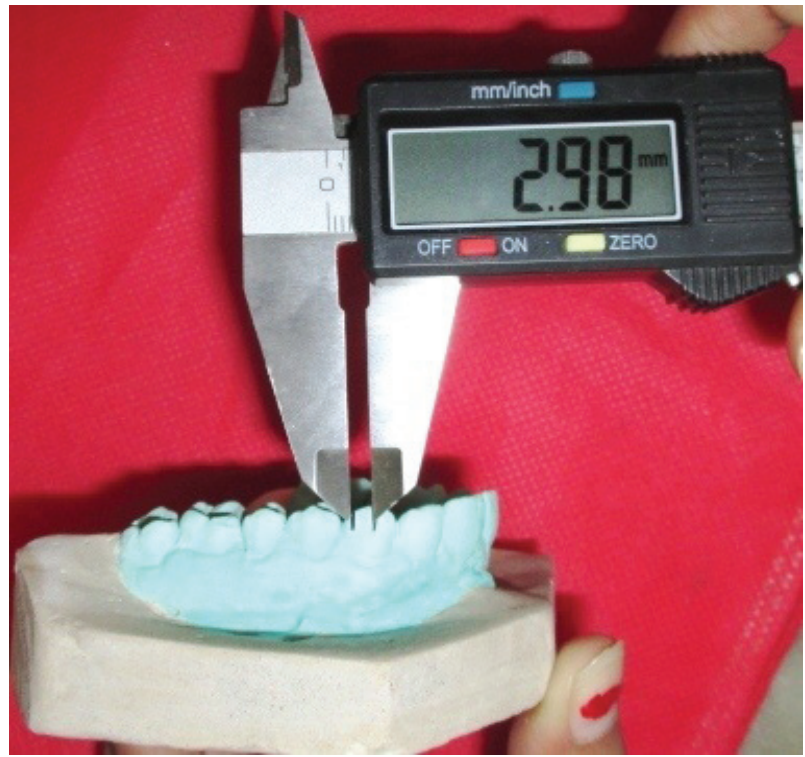

Figure 1: Superimposition of arch form templates on maxillary cast

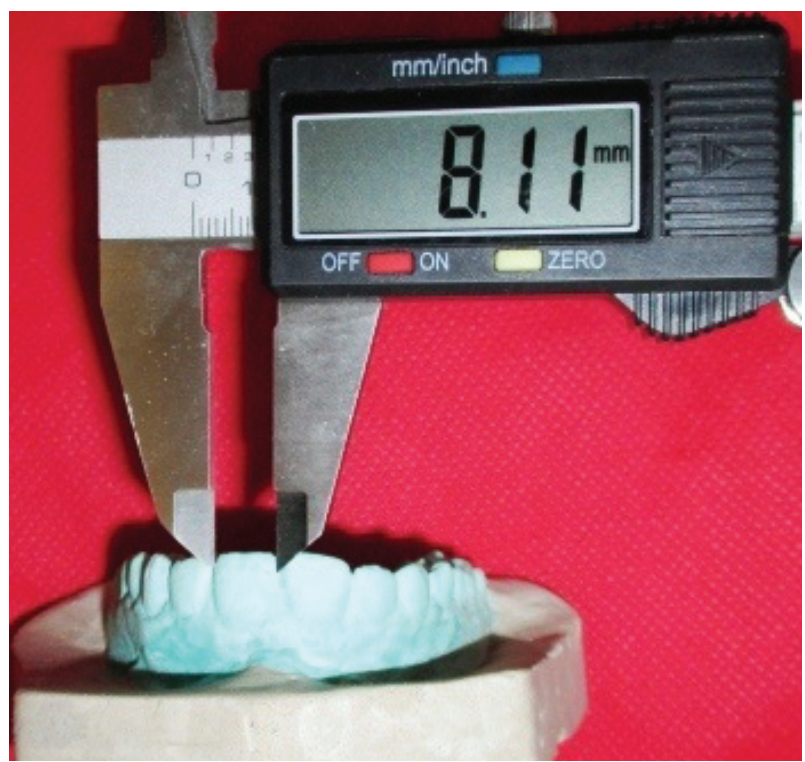

Figure 3: Measurement of distance between tip of canine and commissure of mouth

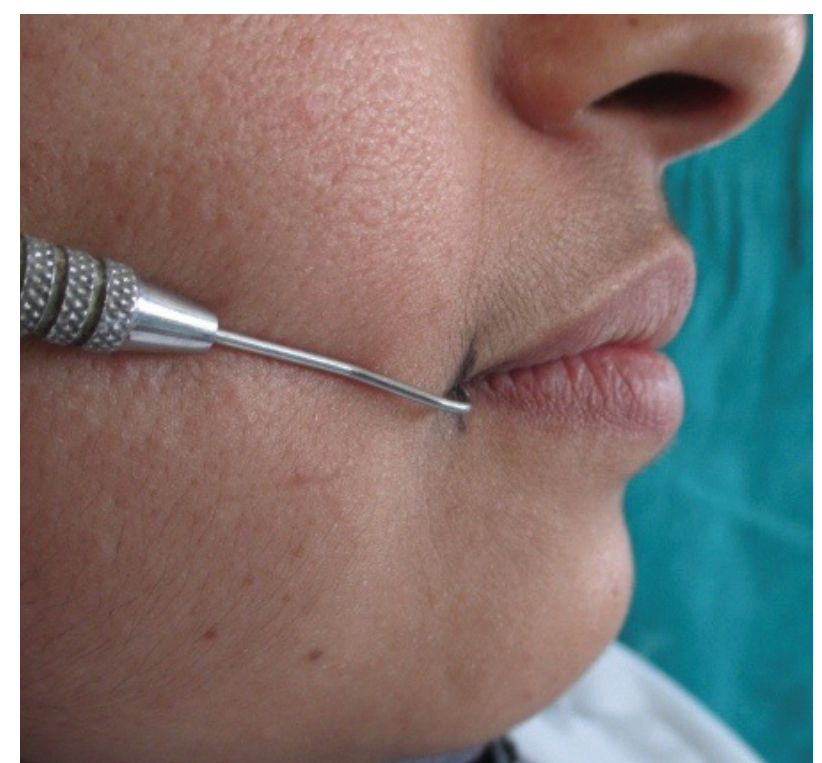

Figure 2: Marking of commissure of mouth on buccal surface of template

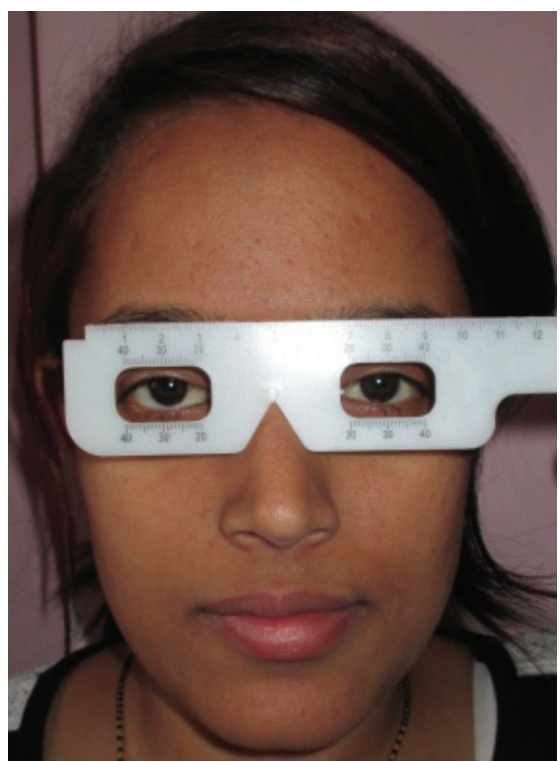

Figure 4: Measurement of Interpupillary distance 


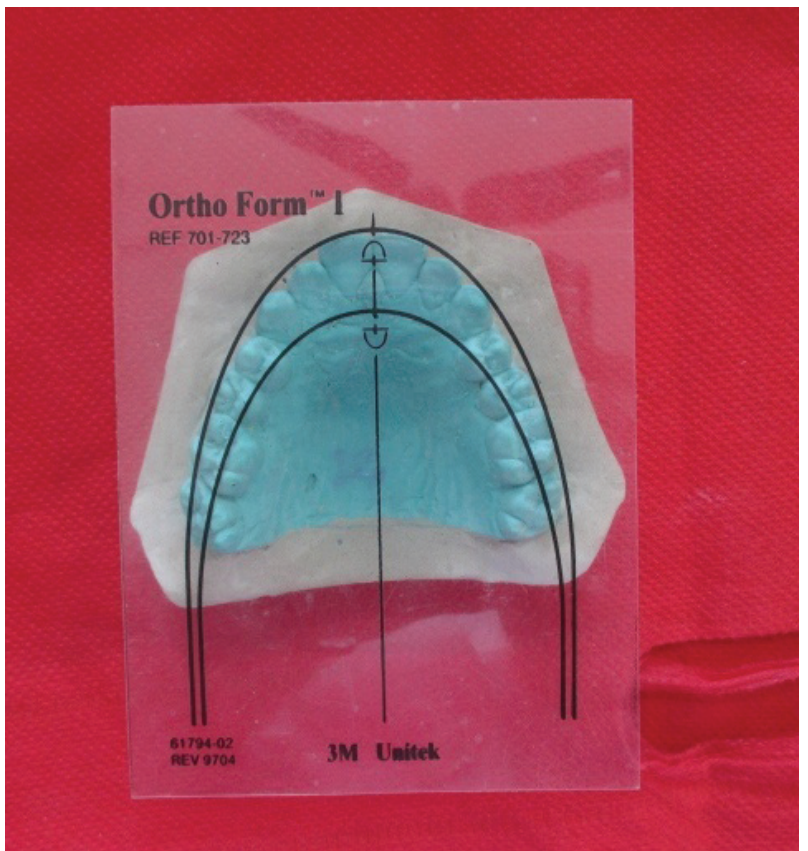

Figure 5: Measurement of Central Incisor width

$$
\frac{\mathrm{IPD}-\mathrm{ICW}}{2}
$$

\section{Discussion}

Esthetic aspect of complete denture rehabilitation is a blend of science and art. Selection and arrangement of maxillary anterior teeth for edentulous patient in a natural and esthetically pleasing form thus becomes a challenging task. ${ }^{6}$ Pre extraction records such as diagnostic casts, photographs, roentgenograms, extracted teeth serve as a reliable guide for selection of teeth. In absence of preextraction records, various facial measurements as width of mouth, interalar width, bizygomatic width, interpupillary distance and intercanthal distance have been proposed in the literatures to estimate the width of anterior teeth. ${ }^{7,8}$

This finding of medial location of maxillary canine in relation to commissure of mouth was in accordance with the study conducted by Asal et al in 2011 in which most of studied subjects (66\% Egyptians, 70\% Saudis) showed medial location of the canine to the commissures. ${ }^{9}$ The study performed by Al Wazzan et al. in 2001 also showed narrower distance between the distal aspect of canine $(45.16 \pm 3.28)$ than the commissures of the mouth in Saudi population $(50.79 \pm 5.09) .{ }^{10}$ The mean distance of tip of canine from commissure of mouth in square arch form is $2.87 \pm 1.01 \mathrm{~mm}$ exactly coincides with the study conducted by Suwannachat J in 2008 in which intercommissural width was greater than intercanine width by approximately $2.3-2.8 \mathrm{~mm}$ for each side. ${ }^{11}$

However, this study was not in agreement with the earlier study carried out by Lieb et al. in 1967 who reported the moderate correlation between intercuspid and intercommissural measurement but not high enough to be used as a predictive factor. ${ }^{12}$ This study disagrees with the study done by Esan TA et al in 2012 who observed the intercommissural distance to be about 1.75 $-2.45 \mathrm{~cm}$ distal to the intercanine distance on each side. ${ }^{13}$

The result of this study suggest that a statistical significant correlation exists between the tip of maxillary canine to commissure of mouth among square, ovoid and tapering arch form. The correlation was also significant regarding IPD among three different arch forms. The result obtained from the study is not suggested as an exclusive and the most promising method for the selection of size of anterior teeth but as one of the supplement for the other available measures and methods for the selection and positioning of anterior teeth. Further studies should be conducted within Nepalese group of population with larger sample size to define an acceptable biometric ratio of such facial measurements for estimating anterior tooth width for a wider base.

\section{Conclusions}

Within the limitations of this study, the mean position of tip of maxillary canine is mesial to commissure of mouth showing a positive correlation with the commissure of mouth in square, ovoid and tapering arch form. However, the mean position of tip of maxillary canine 
is mesial to midpupillary line showing a weak positive correlation with the midpupillary line in square, ovoid and tapering arch form. This correlation may serve as valuable guideline for selection of size of artificial teeth in accordance with arch form of the patient in our group of population but should be correlated with other clinical findings.

\section{Acknowledgements}

Department of Prosthodontic and maxillofacial prosthetics, People's Dental College and Hospital
All the faculty of Department
Dr. Reshu Agrawal

\section{References}

1. Hasanreisoglu U, Berksun S, Aras K, Arslan I. An analysis of maxillary anterior teeth:facial and dental proportions. The Journal of prosthetic dentistry. 2005;94(6):530-8

2. Ellakwa A, McNamara K, Sandhu J, James K, Arora A, El-Sheikh IK, et al. Quantifying the selection of maxillary anterior teeth using intraoral and extraoral anatomical landmarks. The Journal of Contemporary Dental Practice. 2011;12(6):414-21

3. Patel J, Sethuraman R, Naveen Y, Shah MH. A comparative evaluation of the relationship of inner-canthal distance and inter-alar width to the inter-canine width amongst the Gujarati population. Journal of Advanced Oral Research. 2011;2(3):31-8.

4. Shafique A, Saleem T, Chattha MR. Arch form analyses: A comparison of two different methods. Pakistan Oral \& Dental Journal. 2011;31(2).

5. Sinavarat P, Anunmana C, Hossain S. The relationship of maxillary canines to the facial anatomical landmarks in a group of Thai people. The journal of advanced prosthodontics. 2013;5(4):369-73.

6. Strajnić L, Vuletić I, Vučinić P. The significance of biometric parameters in determining anterior teeth width. Vojnosanitetski pregled. 2013;70(7):653-9.

7. Ibrahimagić L, Čelebić A, Jerolimov V, Seifert D, Kardum-Ivić M, Filipović I. Correlation between the size of maxillary frontal teeth, the width between alae nasi and the width between corners of the lips. Acta stomatologica Croatica. 2001;35(2):175-9.

8. Kristek E, Čelebić A. Analysis of width/length ratios of normal clinical crowns of the maxillary anterior dentition: correlation between dental proportions and facial measurements. International Journal of Prosthodontics. 2007;20(3).

9. Asal Sa, Al-Shehri SA, Rashad HM. Canine location in different maxillomandibular relationships in Egyptians and Saudis. The Saudi Dental Journal. 2011;23(1):37-42.

10. Al Wazzan KA. The relationship between intercanthal dimension and the widths of maxillary anterior teeth. The Journal of prosthetic dentistry. 2001;86(6):608-12 .

11. Suwannachat J. The relationship of interalar width, width of mouth and maxillary intercanine width in Kalasin adult population. Khon Kaen Medical Journal. 2010;32(s3):145-52.

12. Lieb ND, Silverman SI, Garfinkel L. An analysis of soft tissue contours of the lips in relation to the maxillary cuspids. The Journal of prosthetic dentistry. 1967;18(4):292-303.

13. Esan T, Oziegbe O, Onapokya H. Facial approximation: evaluation of dental and facial proportions with height. African health sciences. 2012;12(1):63-8. 